\title{
Sensitization of Pain-Modulating Neurons in the Rostral Ventromedial Medulla after Peripheral Nerve Injury
}

\author{
Jonathan D. Carlson, Jennifer J. Maire, Melissa E. Martenson, and Mary M. Heinricher \\ Department of Neurological Surgery, Oregon Health \& Science University, Portland, Oregon 97239
}

Nerve injury can lead to mechanical hypersensitivity in both humans and animal models, such that innocuous touch produces pain. Recent functional studies have demonstrated a critical role for descending pain-facilitating influences from the rostral ventromedial medulla (RVM) in neuropathic pain, but the underlying mechanisms and properties of the relevant neurons within the RVM are essentially unknown. We therefore characterized mechanical responsiveness of physiologically characterized neurons in the RVM after spinal nerve ligation, a model of neuropathic pain that produces robust mechanical hyperalgesia and allodynia. RVM neurons were studied 7-14 $\mathrm{d}$ after spinal nerve ligation, and classified as "on-cells," "off-cells," or "neutral cells" using standard criteria of changes in firing associated with heat-evoked reflexes. On-cells are known to promote nociception, and off-cells to suppress nociception, whereas the role of neutral cells in pain modulation remains an open question. Neuronal and behavioral responses to innocuous and noxious mechanical stimulation were tested using calibrated von Frey filaments $(4-100 \mathrm{~g})$ applied to the hindpaws ipsilateral and contralateral to the injury, and in sham-operated and unoperated control animals. On- and off-cells recorded in nerve-injured animals exhibited novel responses to innocuous mechanical stimulation, and enhanced responses to noxious mechanical stimulation. Neuronal hypersensitivity in the RVM was correlated with behavioral hypersensitivity. Neutral cells remained unresponsive to cutaneous stimulation after nerve injury. These data demonstrate that both on- and off-cells in the RVM are sensitized to innocuous and noxious mechanical stimuli after nerve injury. This sensitization likely contributes to allodynia and hyperalgesia of neuropathic pain states.

Key words: neuropathic pain; spinal nerve ligation; descending control; pain modulation; on-cells; off-cells

\section{Introduction}

Pain after nerve injury has long been explained by increased excitability of primary afferents and sensitization of dorsal horn nociceptive circuits (Campbell and Meyer, 2006). However, more recent behavioral studies have revealed that brainstem modulatory systems such as the rostral ventromedial medulla (RVM) also play a critical role. Although the RVM can facilitate or suppress nociception, inactivation of this region interferes with the mechanical allodynia and hyperalgesia considered central manifestations of neuropathic pain. This indicates that the facilitating outflow from the RVM is dominant after nerve injury (Pertovaara et al., 1996) (for review, see Porreca et al., 2002; Fields et al., 2005).

RVM neurons are functionally heterogeneous, and we have only limited understanding of the cellular and network properties of RVM neurons that might be relevant to neuropathic pain. Only a few studies have examined how nerve injury influences neuronal responsiveness in the RVM, and these studies failed to identify changes in either basal or noxious-evoked discharge of RVM neurons (Luukko and Pertovaara, 1993; Pertovaara and

Received Aug. 15, 2007; revised 0ct. 1, 2007; accepted 0ct. 24, 2007.

This work was supported by National Institute on Drug Abuse Grant DA05608.

Correspondence should be addressed to Mary M. Heinricher, Department of Neurological Surgery, CR137, Oregon Health \& Science University, 3181 Southwest Sam Jackson Park Road, Portland, OR 97239. E-mail: heinricm@ohsu.edu.

D01:10.1523/JNEUROSCI.3715-07.2007

Copyright $\odot 2007$ Society for Neuroscience $\quad$ 0270-6474/07/2713222-10\$15.00/0
Wei, 2000; Pertovaara et al., 2001). This may have been at least in part because the neurons recorded were not functionally characterized. An approach based on current understanding of functionally distinct populations of RVM neurons and their role in bidirectional control from the RVM might therefore clarify how this region contributes to nerve injury pain.

We considered three populations of neurons that can be identified in the RVM based on physiological and pharmacological properties (Fields et al., 2005; Heinricher and Ingram, 2007). One population, "off-cells," inhibits nociceptive processing, and these neurons are characterized by an abrupt decrease in firing just before the occurrence of nocifensive reflexes such as the heatevoked tail flick response. "On-cells" display a sudden increase in activity beginning just before nocifensive reflexes, and are now recognized to promote nociception. The remaining neurons are termed "neutral cells" and show no reflex-related changes in firing. In lightly anesthetized animals, activation of off-cells leads to thermal hypoalgesia, and selective activation of on-cells produces thermal hyperalgesia (Heinricher and Tortorici, 1994; Heinricher et al., 1994; Heinricher and Neubert, 2004; Neubert et al., 2004). A shift in the balance of RVM circuitry such that on-cell activity predominates over that of off-cells mediates the facilitating influence of the RVM in acute inflammation (Kincaid et al., 2006; Xu et al., 2007), and indirect evidence points to on-cells as specifically involved in allodynia and hyperalgesia after nerve injury (Kovelowski et al., 2000; Porreca et al., 2001). There is also evidence that serotonergic neurons, usually considered a subset 
of neutral cells, contribute to nociceptive modulation in abnormal pain states (Suzuki et al., 2004).

On-cells or neutral cells could thus contribute to allodynia and hyperalgesia after nerve injury, and the goal of the present study was to characterize the mechanical responsiveness of identified RVM neurons after nerve injury. We now demonstrate that both on- and off-cells in the RVM display novel activation and prolonged responses to mechanical stimulation after nerve injury, and that this activation is associated with behavioral hypersensitivity.

\section{Materials and Methods}

All experimental procedures followed the guidelines of the Committee for Research and Ethical Issues of the International Association for the Study of Pain (Zimmermann, 1983), and were approved by the Institutional Animal Care and Use Committee at Oregon Health \& Science University. The experiments were performed in male Sprague Dawley rats (Taconic, Germantown, NY) weighing between 250 and 350 g. Three groups of rats were studied. The first underwent an L5 and L6 spinal nerve ligation to generate a model of nerve injury pain (Kim and Chung, 1992). The second group had sham surgery. The third group comprised unoperated controls that were not anesthetized and had no surgery before the day of microelectrode recording.

Spinal nerve ligation procedure. Left L5 and L6 nerve roots were tightly ligated using 4.0 silk suture, according to the Chung model (Kim and Chung, 1992), as follows. Anesthesia was induced and maintained with isoflurane. Using sterile technique, the paraspinal muscles were incised and the anterior portion of the pelvic rim was exposed. The L6 nerve root was mobilized from under the anterior lip of the pelvis and tightly ligated. The L 5 transverse process was removed, and the L 5 nerve root identified and ligated proximal to its union with the L4 root. Sham rats were anesthetized, and the skin and left paraspinal muscles incised, but no additional dissection was undertaken. Rats were monitored after surgery for gross motor deficit, and a small number were killed for this reason.

Behavioral testing before electrophysiological studies. The development of mechanical allodynia in animals subjected to spinal nerve ligation was documented before the electrophysiological recording session. Withdrawal threshold to von Frey filaments was measured before surgery and again 7-10 d afterward, and at the same times in unoperated controls. After a $1 \mathrm{~h}$ accommodation period $(10 \times 20 \mathrm{~cm}$ cage with a wire mesh floor), von Frey filaments were applied to the lateral plantar surface of the left (ipsilateral to injury) and right (contralateral to injury) hindpaws. Filaments of increasing force were applied ( 0.6 up to $100 \mathrm{~g}$, with 60 and $100 \mathrm{~g}$ considered noxious and lower forces innocuous) until the paw was withdrawn (a brisk intentional lifting of the foot from the stimulus, not associated with gait initiation). The withdrawal threshold was defined as the minimum force eliciting a withdrawal on two of three trials. Nerveinjured animals with withdrawal thresholds $>2$ g, and sham-operated rats with thresholds $<8 \mathrm{~g}$ ipsilateral to the procedures were not studied electrophysiologically. Thermal threshold was not tested in awake sessions.

Electrophysiological studies. Microelectrode recording was combined with behavioral testing in lightly anesthetized rats 7-14 d (average, $10 \mathrm{~d}$ ) after surgery. Anesthesia was induced with pentobarbital ( $60 \mathrm{mg} / \mathrm{kg}$, i.p.). The external jugular vein was catheterized for subsequent administration of a short-acting anesthetic and the animal placed in a stereotactic frame. A small craniotomy was drilled over the cerebellum to allow access to the RVM (1.5-2.3 mm caudal to interaural, within $0.3 \mathrm{~mm}$ of midline). Body temperature was maintained at $\sim 37^{\circ} \mathrm{C}$ by a circulating water pad.

A strict anesthetic protocol was necessary because the responsiveness and activity of RVM neurons are influenced by anesthetic fluctuations (Jinks et al., 2004). A continuous infusion of methohexital was used to maintain a constant level of light anesthesia. The dose of methohexital $\left(30-60 \mathrm{mg} \cdot \mathrm{kg}^{-1} \cdot \mathrm{h}^{-1}\right.$, i.v.; mean $\left.\pm \mathrm{SEM}, 45.1 \pm 1.4 \mathrm{mg} \cdot \mathrm{kg}^{-1} \cdot \mathrm{h}^{-1}\right)$ was adjusted so that the animal was resting without signs of discomfort, but light enough that a brisk withdrawal from a $100 \mathrm{~g}$ or lower von Frey fiber was present in sham-operated and unoperated animals and on the side contralateral to the ligation in nerve-injured animals. Mean thresh- old for withdrawal from heat applied to the plantar surface of the left (ipsilateral) foot at this anesthetic plane was $45.6 \pm 0.6^{\circ} \mathrm{C}$, and was not significantly different among groups. The electrophysiological study was not begun until at least $2.5 \mathrm{~h}$ after initial pentobarbital induction, and when the methohexital infusion rate had been unchanged for a minimum of $45 \mathrm{~min}$. Stability of the anesthetic level was further validated by monitoring heart rate, and data were collected only when it was stable.

Cell activity was recorded extracellularly using stainless-steel electrodes (Frederick Haer, Brunswick, ME) plated with gold followed by platinum black. The microelectrode signal was amplified (10k), bandpass filtered $(100 \mathrm{~Hz}$ to $5 \mathrm{kHz}$ ), displayed on an oscilloscope, and digitized (Spike 2; CED, Cambridge, UK). Bilateral hindleg flexor electromyogram (EMG) was used to detect and quantify withdrawal responses to the von Frey fiber and thermal stimulation. The ankle was extended to allow access to the planter region for both the thermal and mechanical stimuli. A mechanical withdrawal reflex was elicited by placing a von Frey fiber on the lateral plantar surface of the foot $(8 \mathrm{~s})$. The most sensitive spot of the foot was determined before starting to collect neuronal activity. This was typically located in the web between the second and third toes, or just proximal. The thermal withdrawal threshold was determined using contact heat from a Peltier device. The temperature of the plantar surface of the paw was ramped from a resting temperature of $35-53^{\circ} \mathrm{C}$ at $1.5^{\circ} \mathrm{C} / \mathrm{s}$. The von Frey filament or heat stimulator was removed from the foot on occurrence of a reflexive withdrawal.

Once a neuron was isolated and characterized as an on-cell, off-cell, or neutral cell, the following experimental protocol was initiated. Three or more thermal noxious stimuli were applied to the left, ipsilateral paw at intervals of at least $5 \mathrm{~min}$. Then three or more trials of mechanical stimulation were applied to the hindpaws (left and right) at each force $(4,6,8$, $10,15,26,60,100 \mathrm{~g})$ in an ascending manner. The beginning of each trial (thermal or mechanical) was timed such that any neuronal response from the previous trial had returned to a period of inactivity (on-cells) or an active phase (off-cells). Thus, for on-cells, a trial was not begun until the neuron had been silent for a minimum of $10 \mathrm{~s}$. For off-cells, the trial was not begun until the cell entered and remained in an active phase for at least $10 \mathrm{~s}$. Because of previously described spontaneous cycling between active and inactive states of on- and off-cells (Barbaro et al., 1989; Heinricher et al., 1989) this typically required a period of 3-5 min between trials, although much longer intertrial intervals were sometimes necessary. Up to four protocols were performed per animal, on a single electrode pass, and in some cases two neurons were recorded simultaneously.

Histology. Recording sites were marked with an electrolytic lesion at the conclusion of the experiment. The rat was killed with an overdose of methohexital, and perfused with $10 \%$ formalin. The locations of all the studied neurons were reconstructed and plotted on standardized sections (Fig. 1). Cells located outside the RVM were excluded from the study.

Analysis. Spikes were sorted off-line (Spike 2), and a periflick time histogram generated around the thermal noxious stimulus. This was used to verify the classification of the neuron as an on-cell (a burst of reflex-related activity when the heat stimulus was applied during a silent period), an off-cell (a pause of at least $1 \mathrm{~s}$ beginning before the reflex when the heat stimulus was applied during an active period), or a neutral cell (no change in activity) as originally described by Fields et al. (1983). The basal firing rate was measured as the number of spikes in the first 4 min of the recording, before any stimulation. The peak firing rate was measured for on-cells for each trial, using $1 \mathrm{~s}$ bins beginning at the burst onset (thermal- or mechanical-evoked). The on-cell burst duration was measured from the first spike of the burst until the last spike before a silent period lasting at least $1 \mathrm{~s}$. The duration of the off-cell pause was measured from the last spike before the paw withdrawal to the first spike after the behavioral withdrawal. For neutral cells, perievent time histograms were generated around the onset of the thermal or mechanical stimulus. To verify the absence of a stimulus-related change in firing rate in these neurons, spike count in the $10 \mathrm{~s}$ before stimulus onset was compared with that during the stimulus and in the $10 \mathrm{~s}$ after the filament was removed.

The minimum von Frey fiber force that elicited a paw withdrawal for 


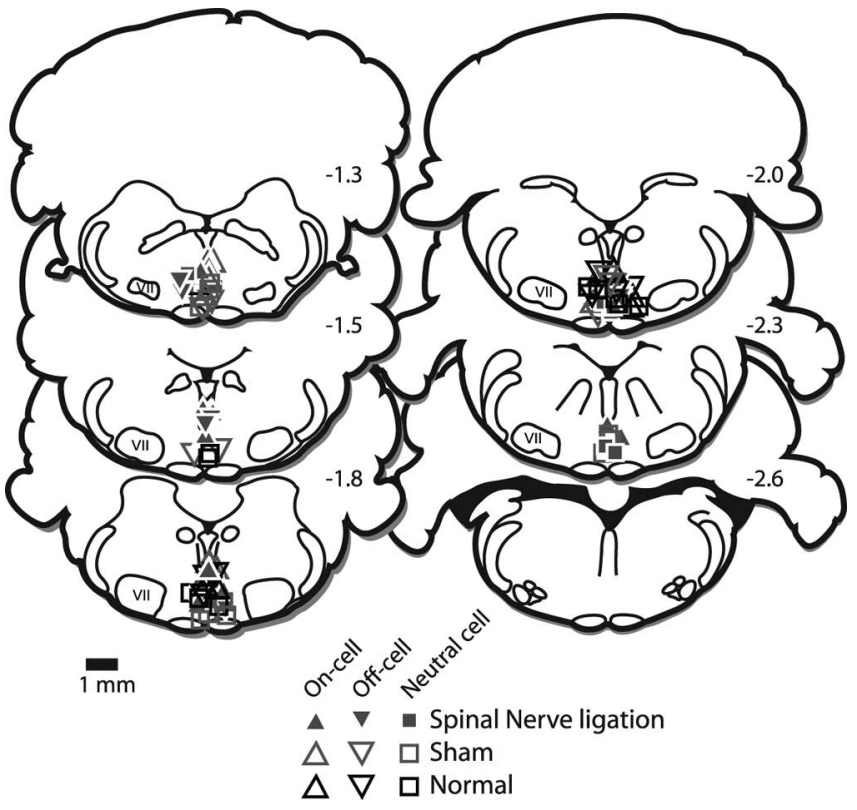

Figure 1. Histologically verified locations of recording sites in nerve-injured (filled symbols) and control (open symbols) animals. VII, Facial nucleus. The distance from the interaural line is indicated. Sections are adapted from Paxinos and Watson (1997). The distribution of neurons recorded in nerve-injured rats overlapped that for those recorded in unoperated and shamoperated controls.

each hindpaw was determined from the EMG and by careful observation at the time of each stimulus. The latency from the onset of the thermal or mechanical stimulus to the paw withdrawal as seen in the EMG record was measured. The magnitude of the withdrawal was estimated from the EMG, which was rectified and smoothed $(0.05 \mathrm{~s})$. The EMG waveform was then averaged over three trials at each von Frey force, and the area under the curve was determined. For heat stimulation, the temperature at which the paw withdrawal reflex occurred was measured for each thermal noxious trial, and an average threshold was determined for each animal.

Data are presented as mean \pm SE. A value of $p<0.05$ was considered statistically significant. In general, paw withdrawal thresholds (von Frey fiber forces) were compared using nonparametric statistics (KruskalWallis ANOVA by ranks, Wilcoxon's signed ranks test). Reflex latencies and magnitudes, ongoing and peak firing rates, and burst and pause durations were compared parametrically (ANOVA followed by Newman-Keuls or Dunnett's post hoc tests, and $t$ tests).

\section{Results}

Similarity of RVM neuron responses to thermal or mechanical noxious stimuli in control animals

Whether the on-cell/off-cell/neutral cell classification applies to reflexes evoked by mechanical as well as thermal noxious stimulation has been controversial (Ellrich et al., 2000; Schnell et al., 2002; Mason, 2005). It was therefore necessary to characterize the mechanical responsiveness of these neurons in control animals before evaluating their responses to tactile stimulation after nerve injury. On-, off-, and neutral cells were identified in shamoperated and unoperated animals using the standard criteria related to heat-evoked withdrawal (Fields et al., 1983). Responses of those same neurons during paw withdrawal evoked by mechanical stimulation of the plantar surface of the paw using a $100 \mathrm{~g}$ von Frey fiber were then characterized, and compared with those seen during heat-evoked behaviors.

As shown in the example of an on-cell and off-cell recorded simultaneously (Fig. 2), reflex-related changes in cell firing were comparable whether the paw withdrawal was evoked by heat (Fig.
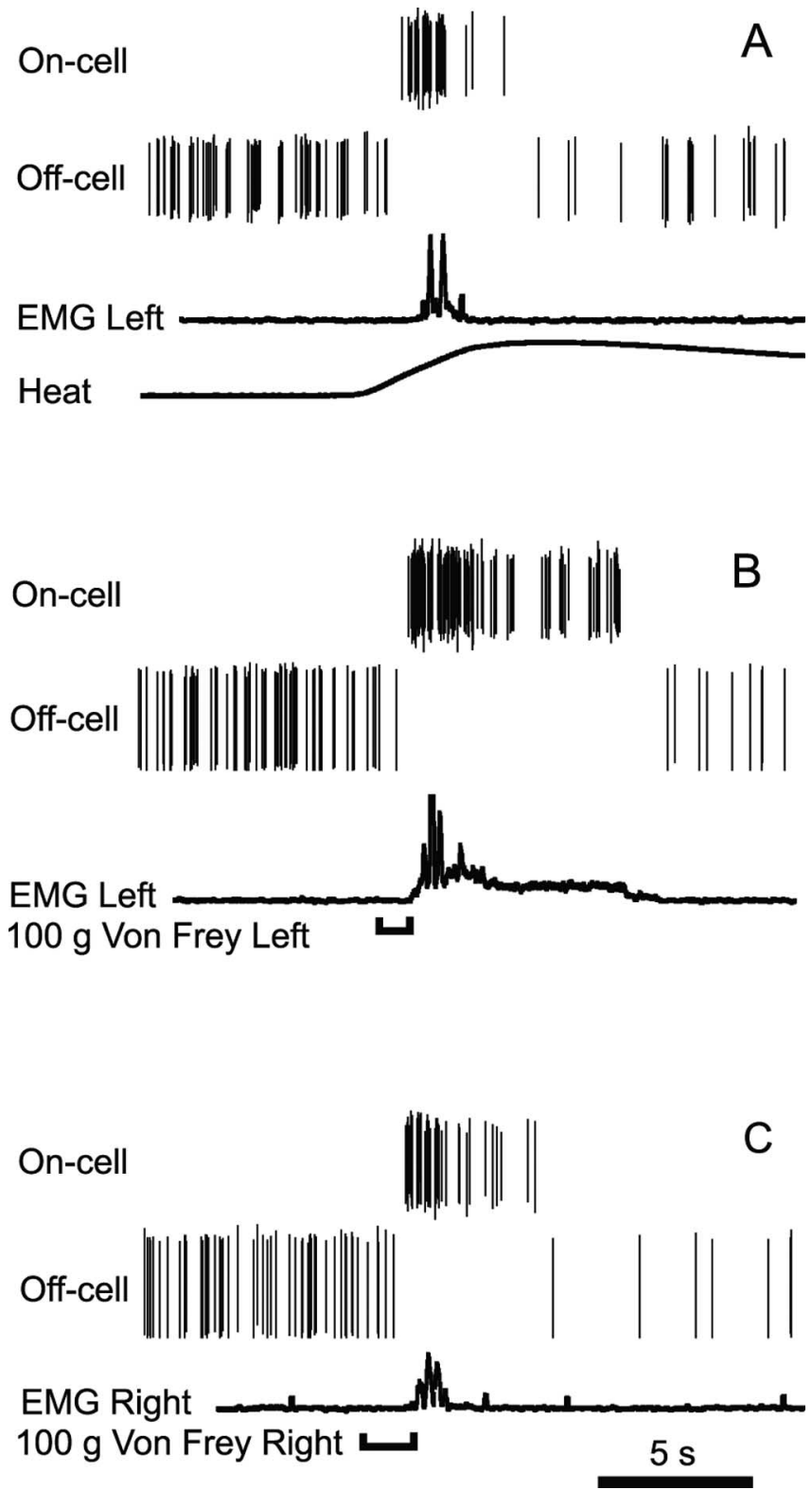

Figure 2. A-C, An on-cell and off-cell recorded simultaneously in a normal, unoperated control animal illustrate characteristic burst and pause associated with reflex evoked by noxious heat $(\boldsymbol{A}), 100 \mathrm{~g}$ von Frey fiber applied to the left hindpaw $(\boldsymbol{B})$, and $100 \mathrm{~g}$ von Frey fiber applied to the right hindpaw (C). EMG trace was rectified and smoothed $(0.05 \mathrm{~s})$ to show the magnitude and timing of the withdrawal. Individual spikes are shown for each cell. Heat stimulus (ramped from a hold temperature of $35^{\circ} \mathrm{C}$ to a maximum of $53^{\circ} \mathrm{C}$ at $1.5^{\circ} \mathrm{C} / \mathrm{s}$ ) was delivered using contact Peltier device. The time of von Frey fiber application is indicated by a bracket below the trace.

$2 A$ ) or by the noxious mechanical stimulus (Fig. $2 B, C$ ). All oncells tested displayed a burst in activity to mechanical noxious stimulation $(n=17)$. Moreover, peak firing rate associated with stimulation of the left hindpaw was similar whether mechanical or thermal stimulation was used to evoke the paw withdrawal (von Frey stimulation, $12.2 \pm 3.0 \mathrm{~Hz}$; heat stimulation, $12.5 \pm 2.8$ $\mathrm{Hz}$ ). Mechanical stimulation of the contralateral (right) foot produced comparable activation of the neurons $(10.6 \pm 0.9 \mathrm{~Hz})$ (ANOVA, $p>0.05$; no effect of stimulus type or site).

Similarly, all off-cells displayed a pause in activity in response to mechanical noxious stimulation $(n=17)$. Moreover, the duration of the off-cell pause was comparable whether the withdrawal was evoked using heat $(20.8 \pm 6.0 \mathrm{~s})$ or the $100 \mathrm{~g}$ von Frey 
fiber (left paw, $24.2 \pm 10.3 \mathrm{~s}$; right paw, $15.7 \pm 7.4 \mathrm{~s}$; ANOVA, $p>$ 0.05 ; no effect of stimulus type or side).

Neutral cells, defined as showing no change in activity related to heat-evoked withdrawal, also uniformly failed to respond to mechanical noxious stimulation $(n=19)$, with no change in firing rate during application of the von Frey filament or immediately after its removal (ANOVA, $p>0.05$ compared with prestimulus period).

On-cells and off-cells thus responded in a qualitatively and quantitatively similar manner during withdrawals evoked by heat and by a noxious punctate mechanical stimulus. Neutral cells were unresponsive during both heat-evoked and mechanically evoked reflexes. RVM neurons can therefore be classified as oncells, off-cells, and neutral cells based on reflex-related changes in firing or the absence of such changes whether that reflex is evoked by a thermal or mechanical noxious stimulus. In addition, noxious mechanical stimulation of the left or right paws elicited similar neuronal responses, which argues against a somatotopic preference for these neurons.

\section{Nerve injury produced mechanical hypersensitivity in lightly anesthetized rats}

Nerve injury led to marked mechanical hypersensitivity on the ligated side, in both the awake and anesthetized state. When tested $\sim 1$ week after surgery while awake, nerve-injured animals showed a significantly lower paw withdrawal threshold on the ligated side compared with the contralateral, nonligated side (Fig. 3). Paw withdrawal thresholds on the left and right sides were not significantly different from one another in the sham-operated and unoperated groups, nor were there significant differences in threshold between these two control groups.

Paw withdrawal threshold was subsequently retested under anesthesia during the electrophysiological experiments, and was substantially elevated under anesthesia compared with the awake state in all groups. Thresholds measured in the unoperated and sham-operated groups under anesthesia were in the range normally considered noxious (60 or 100 g von Frey fiber) (Fig. 3). Animals in the nerve-injured group maintained a clear mechanical hypersensitivity in the side ipsilateral to the ligation (left), with a significantly lower threshold compared with the nonligated side (right), and to the unoperated and sham-operated animals (Fig. 3). Moreover, the latency for paw withdrawal on the ligated side decreased, and the magnitude of the withdrawal increased, as the stimulus force was increased throughout the innocuous range in nerve-injured animals (Fig. 4). Animals subjected to spinal nerve ligation thus displayed a graded allodynia under light barbiturate anesthesia.

In addition to the decrease in withdrawal threshold into the innocuous range ("allodynia"), animals with nerve injury also displayed mechanical hyperalgesia under anesthesia, manifested as a shorter latency for withdrawal to noxious stimulation of the ligated side compared with the paw on the contralateral side. Latencies on the injured side were also significantly shorter than those displayed by unoperated and sham-operated control animals (Fig. 4, responses to 60 and 100 g von Frey filaments). Although the paw withdrawal magnitude increased through the innocuous range on the injured side, this parameter reached a plateau at noxious forces, with no difference among groups in the magnitude of the EMG response evoked using the $100 \mathrm{~g}$ stimulus (Fig. 4) or noxious heat (data not shown) (ANOVA, $p>0.05$ ).

Mechanical stimulation of the paw on the ligated side thus evoked a graded response, with a decreasing latency and an increasing response magnitude as stimulus force was increased. The
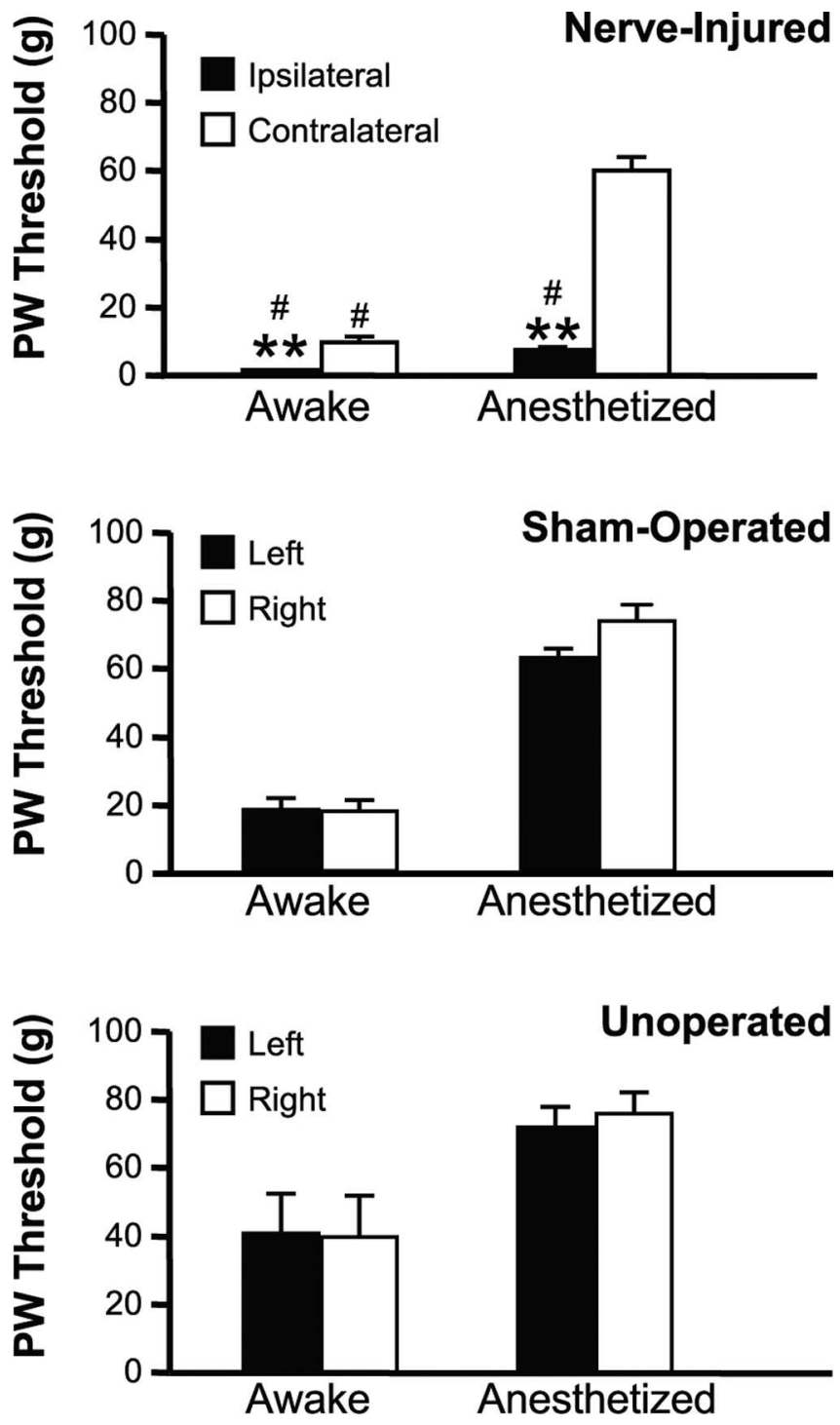

Figure 3. Mechanical withdrawal thresholds obtained while animals were awake and then again under light methohexital anesthesia during neuronal recording session. When nerveinjured animals were tested while awake, the paw withdrawal (PW) threshold ipsilateral to the ligation was significantly lower than on the contralateral side (Wilcoxon's signed ranks test, $p<0.001$ ), and thresholds both ipsilateral and contralateral to the ligation were significantly different from sham-operated and unoperated controls (Kruskal-Wallis, $p=0.0004$ ). In comparison with thresholds obtained during awake testing, thresholds were elevated when subsequently retested under anesthesia during electrophysiological studies, but mechanical allodynia was maintained ipsilateral to the lesion (threshold on the ligated side significantly less than nonligated; Wilcoxon's signed ranks test, $p<0.001$; and compared with unoperated or sham-operated groups, Kruskal-Wallis, $p<0.0001$ ). Thresholds of sham-operated animals were not significantly different from normal unoperated controls in any case (mean \pm SEM; ${ }^{\#} p<0.05$ compared with unoperated animals; ${ }^{* *} p<0.01$ compared with nonligated side; 10-18 animals per group).

latency to respond to a noxious von Frey stimulus was also reduced in nerve-injured animals compared with sham-operated and unoperated controls. Thus, both allodynia and mechanical hyperalgesia were detectable under light methohexital anesthesia after nerve injury.

Thermal withdrawal was tested only under anesthesia. In contrast with mechanical allodynia and hyperalgesia, thermal hyperalgesia was not seen after nerve injury in the lightly anesthetized animals. That is, there was no difference in the temperature at which paw withdrawal occurred among unoperated, sham- 


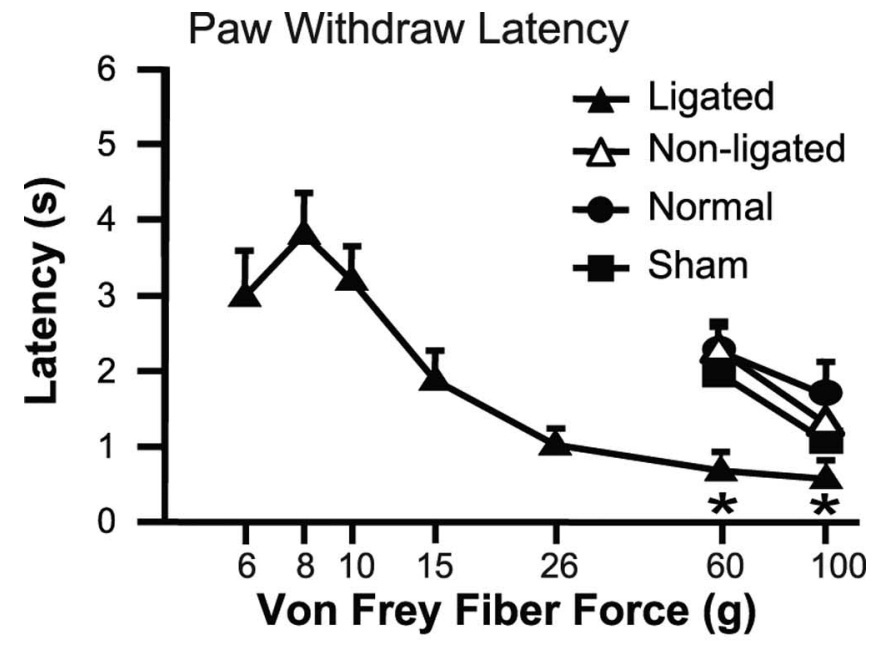

Paw Withdrawal Magnitude

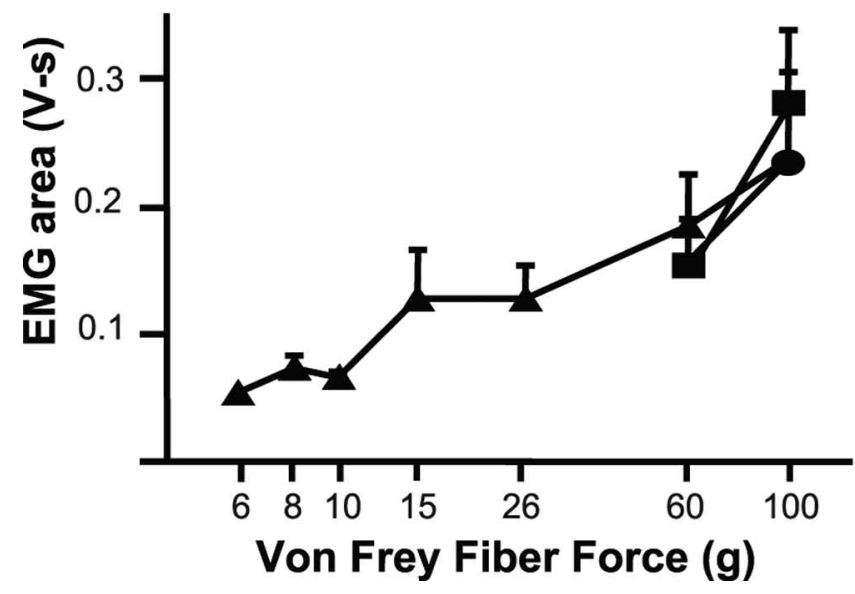

Figure 4. Paw withdrawal (PW) latency and magnitude evoked by various von Frey filaments. The paw withdrawal latency was measured from the application of the von Frey fiber to the paw withdrawal detected by EMG. The paw withdrawal magnitude was measured as the area under the rectified smoothed EMG curve. In nerve-injured animals, stimulation of the paw on the ligated side evoked reflex withdrawals when innocuous forces were applied $(6,8,10$, $15 \mathrm{~g})$. Unoperated and sham-operated animals responded only to stimuli of noxious intensities (60 and $100 \mathrm{~g}$ ). The paw withdrawal latency decreased, and the paw withdrawal magnitude increased, as the von Frey fiber force increased, in both cases showing a significant linear trend (within-subject ANOVA, $p<0.0001 ; n=18$ ). With stimulation at noxious intensity, nerveinjured animals responded with a significantly shorter latency to stimulation of the ligated paw compared with nonligated, and to unoperated or sham-operated controls $\left({ }^{*} p<0.05\right.$, ligated compared with nonligated side, as well as to unoperated and sham-operated controls; $n=$ $10-18$ animals per group). Magnitude of the response reached an apparent maximum at 60 and $100 \mathrm{~g}$, so that the response evoked from the nerve-injured animals was not different from that produced in unoperated and sham-operated controls. Data are expressed as mean \pm SEM.

operated, and nerve-injured animals $\left(45.6 \pm 0.6^{\circ} \mathrm{C}\right.$; ANOVA, $p>$ $0.05 ; n=10-18$ animals/group).

\section{On-cell responses after nerve injury}

Responses of on-cells to both innocuous and noxious mechanical stimuli were altered after nerve injury. On-cells recorded in nerve-injured rats $(n=11)$ displayed a burst of activity associated with withdrawals evoked by innocuous mechanical stimulation, as illustrated in the example of Figure 5. Mechanical stimulation as low as $6 \mathrm{~g}$ applied to the ligated paw produced a neuronal response concomitant with the withdrawal reflex (shown in the
EMG traces below the neuronal data). In contrast, mechanical stimulation of the nonligated paw evoked neuronal and behavioral responses only at noxious forces (60 and $100 \mathrm{~g}$ filaments). On-cells recorded in unoperated $(n=8)$ and sham-operated controls $(n=9)$ responded only when stimulus force was sufficient to evoke a withdrawal (Fig. 6, 60 and $100 \mathrm{~g}$ filaments). The on-cell burst was thus tightly linked to the behavioral withdrawal in both control and nerve-injured animals, ipsilateral and contralateral to the injury.

The peak firing rate during the burst evoked by innocuous stimulation of the ligated paw increased with stimulus force in the nerve-injured animals (Fig. 7). On-cell activation after nerve injury thus paralleled allodynia in showing a graded response to tactile stimulation. When the paw withdrawal was evoked by noxious heat or von Frey stimulation at noxious forces (60 or $100 \mathrm{~g}$ filaments), the peak firing rate was equivalent across groups (nerve-injured, unoperated, and sham-operated), demonstrating a ceiling effect in firing rate. Because response magnitude also reached a plateau at noxious levels, this finding is consistent with the recent suggestion that the reflex-related on-cell burst contributes to the force of nocifensor withdrawal (Jinks et al., 2007). However, the duration of the reflex-related burst was prolonged when the ligated paw was stimulated compared with the nonligated paw (35.6 \pm 10.2 vs $8.6 \pm 3.8 \mathrm{~s} ; p=0.03$, paired $t$ test $)$. This is also shown in the cumulative firing rate histogram generated for the on-cells at noxious mechanical stimulation (100 g) on the ligated and for the nonligated paw (Fig. 8). There was a significant increase in the area under the firing rate curve, indicating that the overall neuronal response of the on-cells was larger when the ligated paw was stimulated compared with the nonligated side $(p<0.05$, paired $t$ test $)$.

Basal firing rates in on-cells recorded in nerve-injured, sham operated, and normal animals were comparable (ANOVA, $p>$ $0.05)$.

These data demonstrate sensitization of RVM on-cells to mechanical stimulation of the ligated side after nerve injury. Oncells exhibited a burst of activity that paralleled behavioral allodynia, and reflex-related peak firing rate increased with stimulus force through the innocuous range. In addition, when noxious mechanical stimulation was applied, the on-cell response to stimulation of the nerve-injured side was prolonged and enhanced compared with the contralateral side.

\section{Off-cell responses after nerve injury}

Responses of off-cells to both innocuous and noxious mechanical stimuli were altered after nerve injury. Off-cells recorded in nerve-injured animals $(n=9)$ exhibited a pause in firing associated with withdrawals evoked by innocuous mechanical stimulation, as illustrated in the example of Figure 9. In this animal, mechanical stimulation as low as $8 \mathrm{~g}$ applied to the foot on the ligated side produced a pause concomitant with the withdrawal (shown in the EMG traces below). In contrast, mechanical stimulation of the paw on the contralateral, nonligated side evoked neuronal and behavioral responses only at noxious forces. Offcells recorded in unoperated $(n=6)$ and sham-operated $(n=11)$ control animals responded only when the stimulus force was sufficient to evoke a withdrawal (Fig. 6, 60 and $100 \mathrm{~g}$ fibers). As with the on-cell burst, the off-cell pause was thus tightly linked to the behavioral withdrawal in control as well as in nerve-injured animals.

Although the duration of the off-cell pause is quite variable, it can serve as a reasonably good index of the magnitude of the neuronal response, analogous to peak firing rate measured for the 


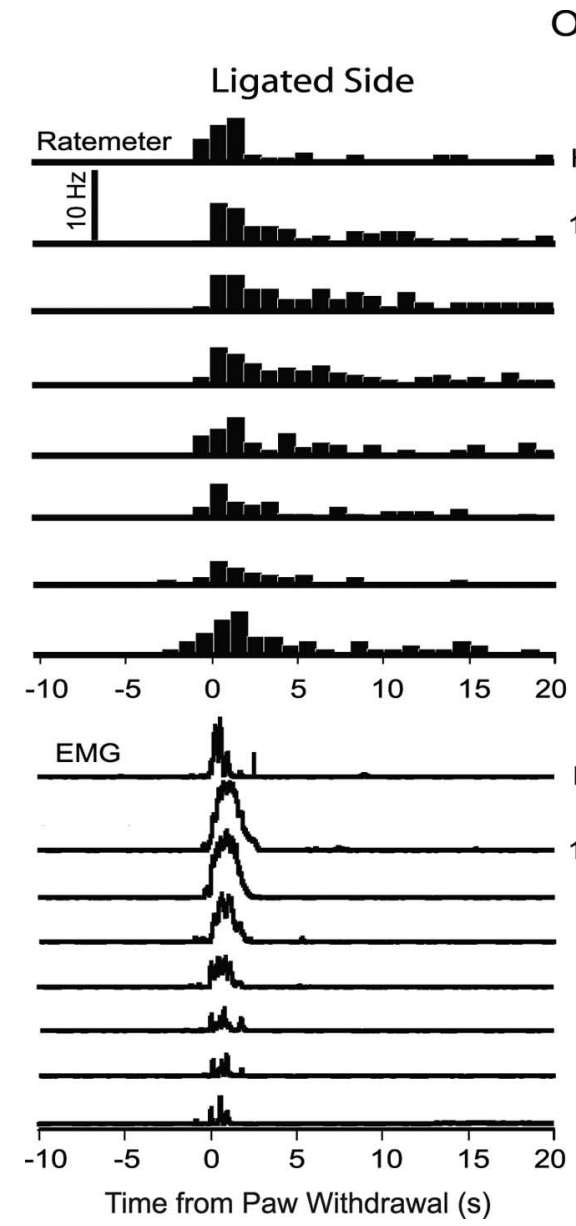

On-cell

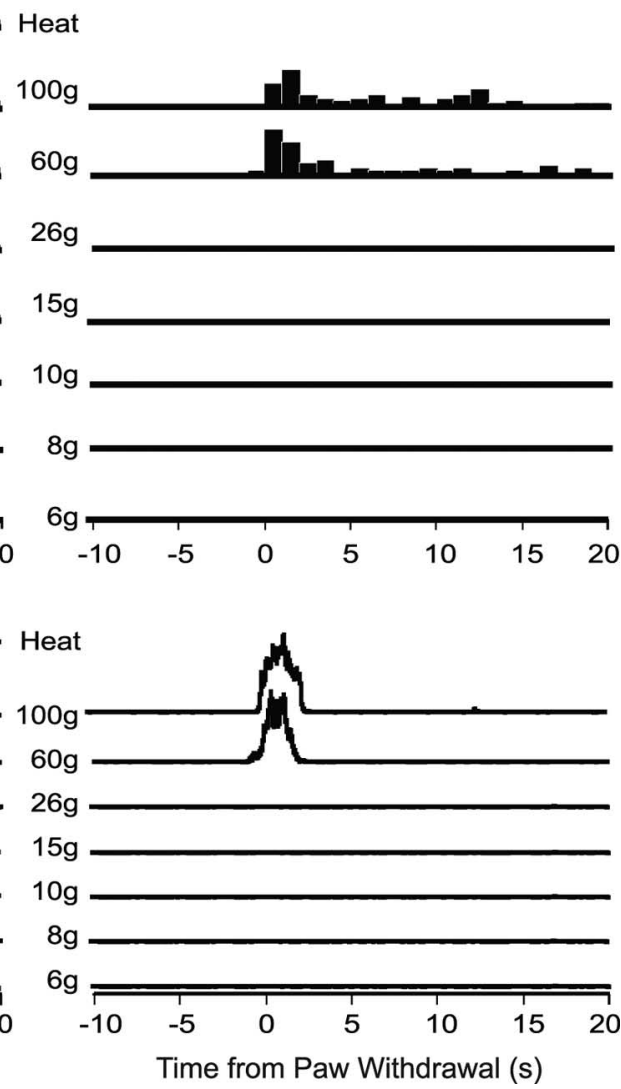

Figure 5. Example of an on-cell response to von Frey fiber stimulation in an animal with nerve injury. Stimulation of the ligated side (left column) compared with the nonligated side (right column). Behavioral responses to the same stimuli are shown below. Histograms of cell activity ( $1 \mathrm{~s}$ bins) and EMG are an average of three trials at each stimulus force, aligned around the onset of the reflex (time 0). A thermal noxious stimulus (heat; applied only on the ligated side) evoked a neuronal and EMG response similar to that elicited by mechanical noxious stimulation of either foot.

on-cell population. The off-cell pause duration increased with stimulus force, and at noxious mechanical stimulus intensities, the off-cell pause was significantly longer with stimulation of the ligated compared with nonligated paw (Fig. 10).

Basal firing rates of off-cells and the duration of the pause associated with heat-evoked withdrawal recorded in nerveinjured, sham-operated, and normal animals were comparable (ANOVA, $p>0.05$ ).

Off-cells, like on-cells, are thus sensitized to mechanical stimulation of the ligated paw, with novel responses to innocuous tactile stimulation that parallel behavioral allodynia, and prolonged responses to noxious mechanical stimulation ipsilateral to the injury.

Neutral cells are unaffected by both thermal and mechanical noxious stimuli

Neutral cells, defined as showing no change in activity associated with a noxious heat-evoked withdrawal reflex, similarly showed no change in activity when mechanical stimulation was used in unoperated, sham-operated, or nerve-injured animals (ANOVA, $p>0.05 ; 6-10$ cells per group). This was not for the lack of behavioral allodynia, as shown in the example in Figure 11, in which a withdrawal was obtained with stimulus forces as low as $6 \mathrm{~g}$. Basal firing rates of neutral cells recorded in nerve-injured, sham-operated, and normal animals were comparable (ANOVA, $p>0.05$ ).

\section{Discussion}

These results demonstrate that on- and off-cells in the RVM develop novel responses to light touch after nerve injury, and display exaggerated responses to noxious mechanical stimulation. Associated with these abnormal neuronal responses are behavioral allodynia and mechanical hyperalgesia, comparable with that demonstrated in awake behaving animals, and generally accepted as a model for neuropathic pain.

\section{Responses of on- and off-cells} are reflex-related

The on/off/neutral cell framework was originally based on changes in firing associated with the withdrawal evoked by application of noxious heat to the tail (Fields et al., 1983). It was subsequently extended to heat-evoked paw withdrawal (Neubert et al., 2004), and further validated by the consistent pharmacology within the different classes (Heinricher and Ingram, 2007). Some authors have nevertheless argued that this classification applies principally, if not exclusively, to noxious heat (Ellrich et al., 2000; Schnell et al., 2002), because a small number of "atypical" neurons reportedly responded differently to noxious heat and pinch. However, in these reports, atypical cells were not classified based on reflex-related activity, and stimulus intensity was not normalized relative to reflex threshold, limiting comparisons to the reflex-related categorization used here.

This issue was critical for the present study, because mechanical allodynia and hyperalgesia are central manifestations of clinically significant neuropathic pain. We therefore systematically compared the responses of RVM neurons during withdrawals evoked by noxious thermal versus mechanical stimulation. These stimuli resulted in similar response patterns in all neurons tested, and response magnitudes were comparable. Moreover, cells identified as neutral cells using heat-evoked withdrawal similarly failed to respond during stimulation using the von Frey filaments. These data emphasize that on- and off-cells should be identified based on nocifensor reflex-related changes in firing regardless of the modality of the cutaneous stimulus used to evoke the reflex, highlighting their role as modulatory, rather than sensory, neurons.

\section{RVM pain-modulating neurons after nerve injury}

Previous investigators failed to identify significant changes in the ongoing or noxious-evoked activity of RVM neurons after nerve injury (Luukko and Pertovaara, 1993; Pertovaara and Wei, 2000; Pertovaara et al., 2001). However, animals in those studies were deeply anesthetized, so it was not possible to classify RVM neurons using reflex-related changes in firing, and effects of innocuous mechanical stimuli were apparently not tested. Using the 

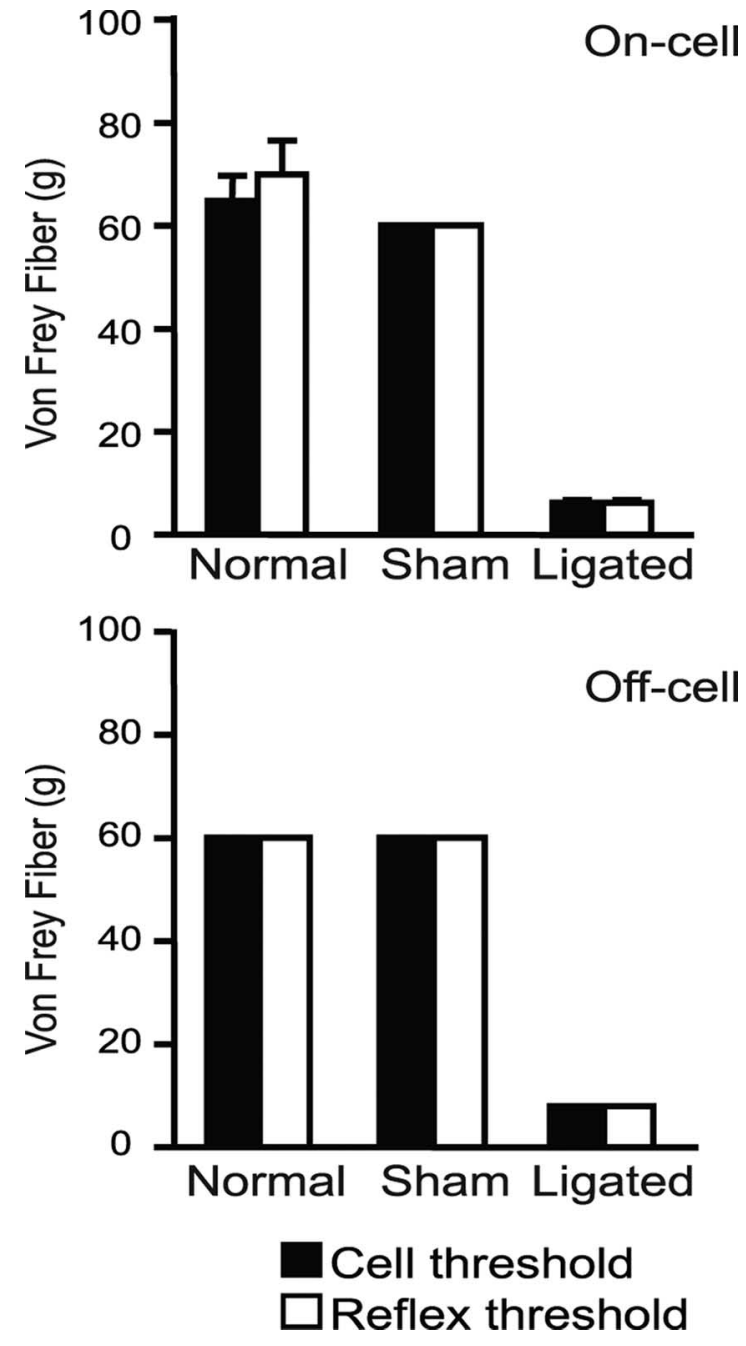

Figure 6. Comparison of the mechanical thresholds for the concurrent behavioral withdrawal and on- and off-cell responses (burst and pause, respectively) to stimulation of the left (ipsilateral) hindpaw. With one exception, behavioral and neuronal thresholds were identical (for on-cells, 8-11 cells per group, for off-cells, 6-11 cells per group; data expressed as mean \pm SEM).

on/off/neutral cell classification and a lightly anesthetized rat preparation with demonstrated behavioral hypersensitivity, we now show enhanced mechanical sensitivity of both on-cells and off-cells. Both classes respond to innocuous punctate stimulation of the paw ipsilateral to the injury, and the neuronal thresholds closely track the withdrawal threshold measured behaviorally. In addition, neuronal responses evoked by frankly noxious stimuli are prolonged. Our findings thus demonstrate altered responses specific to identified pain-modulating neurons in the RVM after nerve injury. Although anesthesia can influence the activity of RVM neurons (Oliveras et al., 1991a,b; Jinks et al., 2004), responsiveness is generally reduced, not enhanced, under anesthesia compared with the awake state, and it is likely that these neurons would be as sensitive or even more sensitive to mechanical stimulation in awake behaving animals.

The on-cell burst and off-cell pause have generally been viewed as all-or-nothing events (Fields and Heinricher, 1985). Our findings in normal animals were consistent with this in that on- and off-cell responses associated with reflexes evoked by noxious heat or high-intensity von Frey stimulation were comparable. It was therefore surprising that the on-cell burst and off-cell

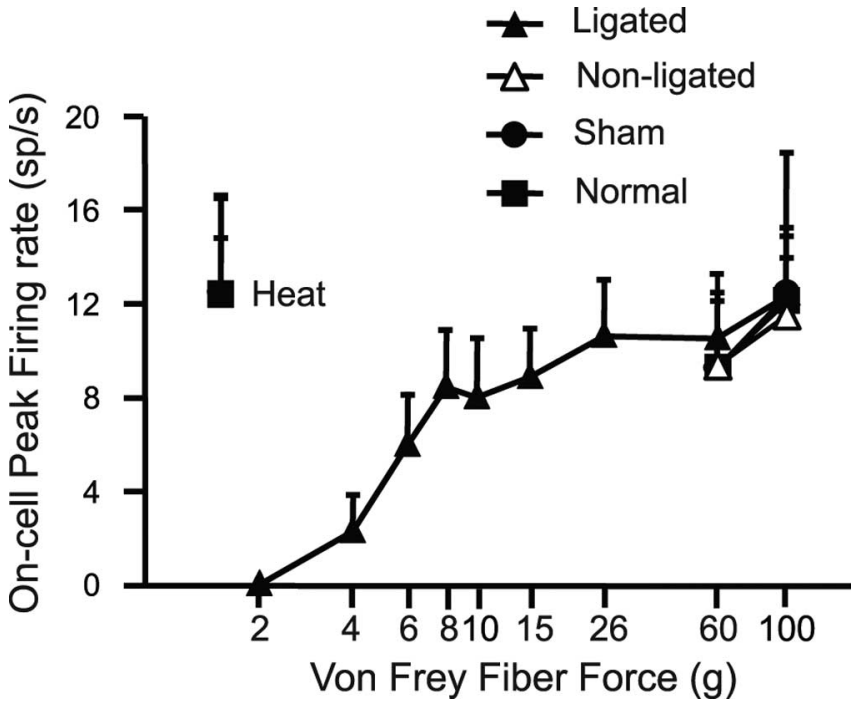

Figure 7. On-cell peak firing rate as a function of the von Frey filament force. Activity recorded during stimulation of the ligated side in nerve-injured animals compared with nonligated side and to activity recorded in sham-operated and normal, unoperated controls. With stimulation of the ligated side, peak firing rate increased in a graded manner with stimulus force through the innocuous range (within-subject ANOVA showed a significant linear trend, $p<$ $0.0001)$. At noxious intensities, peak firing rate was equivalent across groups and similar to activity associated with noxious thermal stimulation (8-11 cells per group; data expressed as mean \pm SEM).

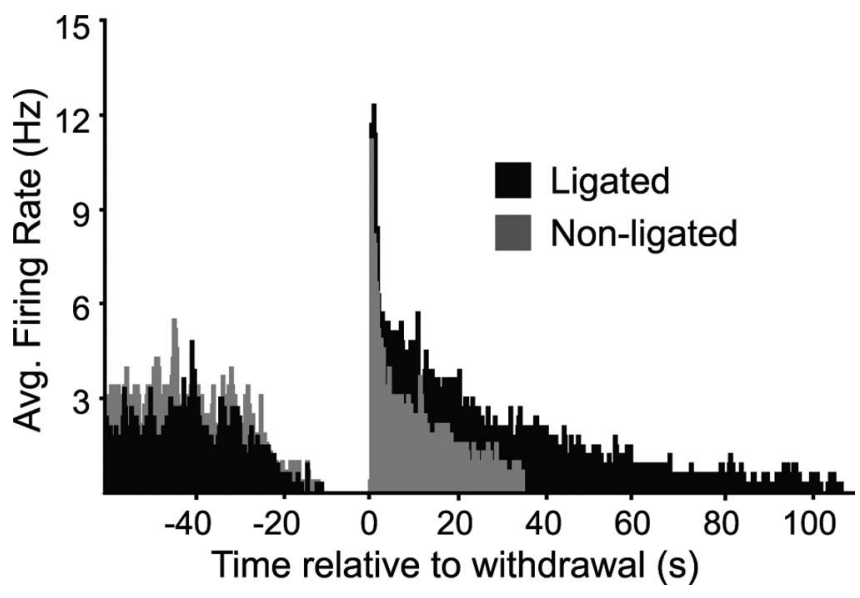

Figure 8. Cumulative spike histogram compares the on-cell population response to noxious mechanical stimulation of the ligated and nonligated paw in nerve-injured animals. The $100 \mathrm{~g}$ von Frey filament, $0.5 \mathrm{~s}$ bins aligned with first spike of on-cell burst. (Analysis includes only a subset of trials on which complete paired data were available; 24 trials, 8 cells.) Although there was no difference in peak firing rate, the overall on-cell response to stimulation of the ligated paw was larger than to stimulation of the nonligated paw.

pause were graded with the intensity of the tactile stimulation delivered to the neuropathic paw. For off-cells, this pattern was continued into the noxious range after nerve injury, and the pause was significantly prolonged when a withdrawal was evoked by stimulation ipsilateral to the injury. For on-cells, intensity coding shifted from firing rate to burst duration as the stimulus reached noxious intensities, which may be analogous to the afterdischarges observed in dorsal horn neurons after nerve injury (Pitcher and Henry, 2000). These data thus reveal a capacity for intensity encoding within the RVM, at least after nerve injury.

The function of neutral cells remains unclear. Spinal $5 \mathrm{HT}_{3}$ receptors have been implicated in nerve injury pain, and a subset 


\section{Off-cell}
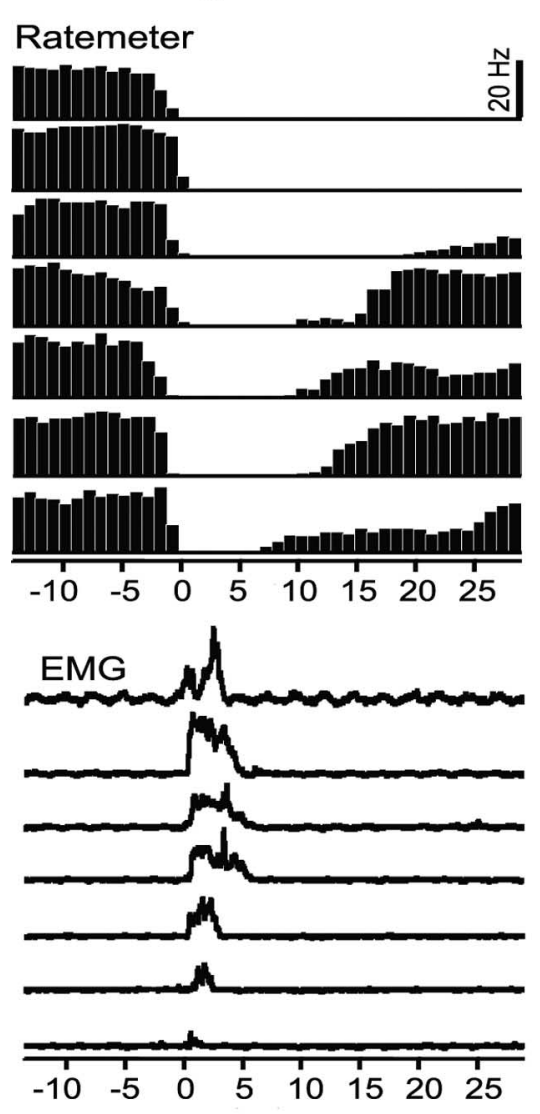

Time from Paw Withdrawal (s)

\section{Non-Ligated Side}
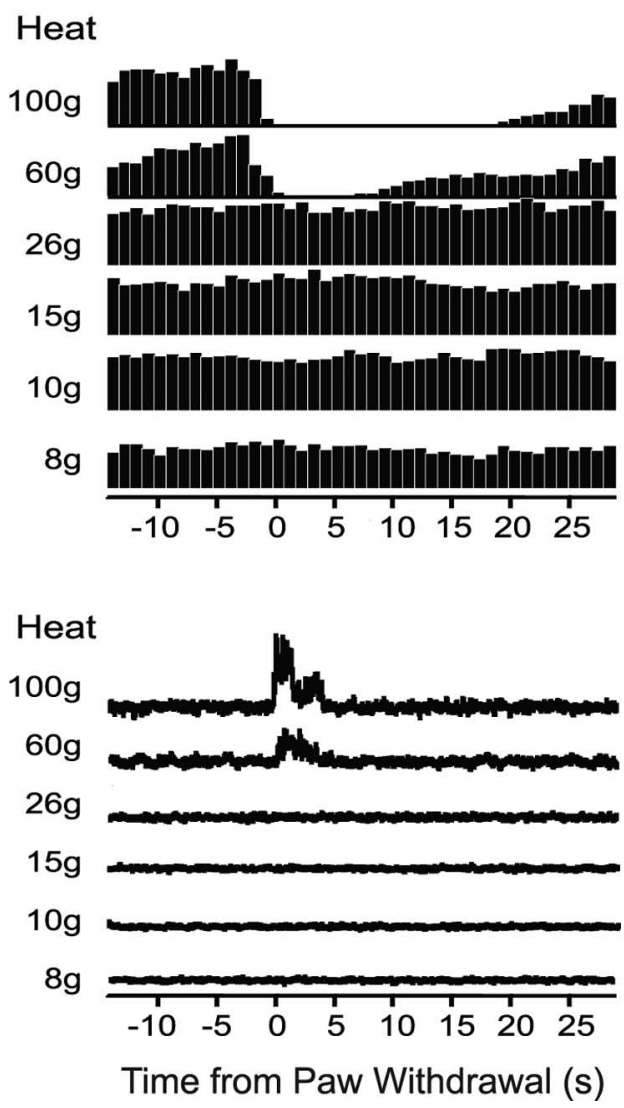

Figure 9. Example of an off-cell response to von Frey fiber stimulation in an animal with nerve injury. Stimulation of the ligated side (left column) compared with the nonligated side (right column). Behavioral responses to the same stimuli shown below. Histograms of cell activity ( $1 \mathrm{~s}$ bins) and EMG are average of three trials at each stimulus force, aligned around the onset of the reflex (time 0 ). A thermal noxious stimulus was applied only on the ligated side (heat) and evoked a neuronal and EMG response similar to that elicited by mechanical noxious stimulation of either foot.

of neutral cells, but not on- and off-cells, are serotonergic, at least in normal animals (Suzuki et al., 2004; Winkler et al., 2006) [but see Zhang et al. (2006) for a different view]. However, it is not impossible that on-cells gain the ability to express serotonin after nerve injury. In addition, some high-threshold or "uncommitted" neurons that would be classified as neutral cells under normal conditions might be recruited into the pain-modulating population of the RVM and develop reflex-related responses after nerve injury (Miki et al., 2002). Unfortunately, in the absence of a preinjury baseline, it is impossible to know whether some of the neurons classified as on-cells or off-cells after nerve injury would have been considered neutral cells if recorded before the injury. These experiments thus provide no information about the stability of the on-cell/off-cell/neutral cell classification with injury, or the role of neutral cells in neuropathic pain.

\section{Role of RVM neurons in pain after nerve injury}

A host of studies using selective activation and inactivation of the different RVM cell classes now clearly demonstrate opposing roles for on-cells and off-cells: on-cells exert a net pronociceptive effect, whereas off-cells have a net antinociceptive effect. Selective activation of on-cells results in hyperalgesia, and hypoalgesia can be produced by disinhibition or activation of off-cells
(Heinricher and Tortorici, 1994; Heinricher et al., 1994; Heinricher and Neubert, 2004; Neubert et al., 2004). These findings are bolstered by correlative observations in different hyperalgesic states including acute inflammation (Kincaid et al., 2006; Xu et al., 2007), acute opioid withdrawal (Bederson et al., 1990; Ossipov et al., 2004), and models of systemic illness and acute stress (Heinricher et al., 2004; Martenson and Heinricher, 2007), all of which are associated with an increase in on-cell firing and suppression of off-cell discharge.

On-cells are activated by cholecystokinin (Heinricher and Neubert, 2004), and studies in awake, behaving animals suggested that an abnormal, cholecystokininmediated input to on-cells plays a critical role in neuropathic pain (Kovelowski et al., 2000; Porreca et al., 2001; Burgess et al., 2002). The present observations of lowered threshold and enhanced responses of both on- and off-cells after nerve injury support this view, but also point to suppression of descending inhibition from off-cells as an additional factor in allodynia and hyperalgesia. It would certainly be useful to examine the development of this abnormal sensitivity in the RVM, because behavioral allodynia and hyperalgesia do not require the RVM for the first several days after the injury (Burgess et al., 2002).

Although we saw no difference in ongoing activity between nerve-injured and control groups, the prolonged burst and pause are likely to be particularly important in behavioral hypersensitivity, particularly in experimental paradigms with repeated testing or with persistent stimulation of the affected area that might occur as part of normal activity. With continued activation of on-cells and inhibition of off-cells, this would result in a shift in the balance within the RVM over time so that output from on-cells predominates over that from off-cells, as in inflammatory paradigms (Kincaid et al., 2006; Xu et al., 2007).

\section{Mechanisms for abnormal RVM activity}

Although increasing behavioral and pharmacological evidence demonstrates an important role for supraspinal circuitry in neuropathic pain states, we have almost no mechanistic information as to how supraspinal circuitry is altered in these conditions. Our findings now document lowered threshold and increased responsiveness of identified pain-modulating neurons in the RVM, but do not reveal the basis for the observed changes. One possibility is that changes in RVM reflect altered peripheral inputs and processing at the level of the dorsal horn, which has been well documented (Campbell and Meyer, 2006). Arguing against this view is the fact that responses of the wide-dynamic range population to von Frey stimulation are reported to be only modestly enhanced or even depressed after spinal nerve ligation (Palecek et al., 1992; Pertovaara et al., 1997; Chapman et al., 1998; Chu et al., 2004). This would suggest that the changes in the RVM do not simply 


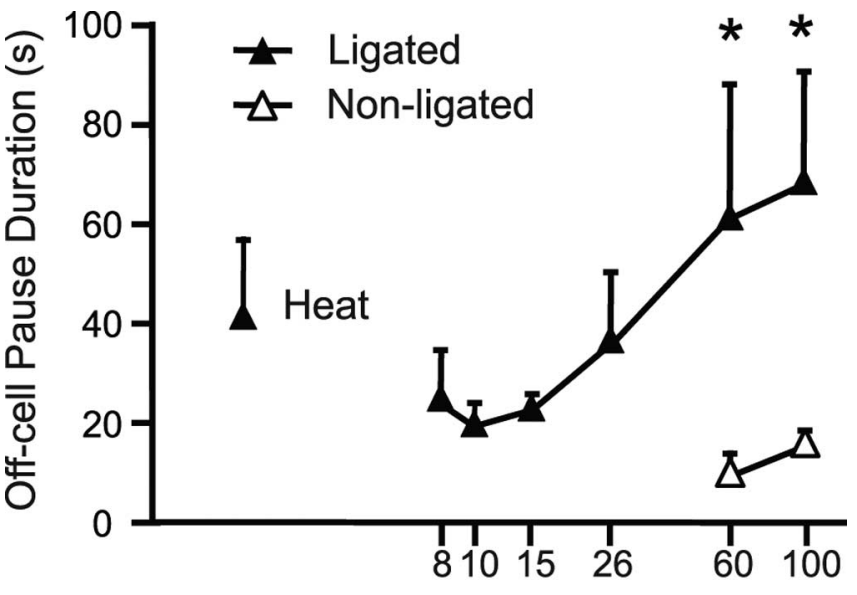

Von Frey Fiber Force (g)

Figure 10. Duration of the off-cell reflex-related pause as a function of the von Frey filament force in nerve-injured animals. Ligated and nonligated sides are compared. With stimulation of the ligated side, pause duration increased in a graded manner as the stimulus force increased (within-subject ANOVA showed a significant linear trend; $p<0.0001 ; n=9$ cells). With stimulation at noxious intensities ( 60 or $100 \mathrm{~g}$ ), the duration of the off-cell pause was significantly longer when the stimulus was applied to the ligated side (mean $\pm \mathrm{SEM} ;{ }^{*} p=0.03$, paired $t$ test).

mirror changes at the level of the dorsal horn. However, if it is assumed that on- and off-cells receive inputs originating from channels that are normally "nociceptive-specific," novel responses in RVM could be explained if such inputs were to develop sensitivity to innocuous stimuli after nerve injury.

Another possible explanation for our findings is sensitization of RVM neurons or of supraspinal centers that influence painmodulating circuits of the RVM (Millecamps et al., 2007; Tracey and Mantyh, 2007). Changes intrinsic to the RVM are well documented during inflammation (Wei et al., 1999; Guan et al., 2002; Miki et al., 2002; Imbe et al., 2005, 2007; Guo et al., 2006), and the behavioral data indicate that the dorsal horn in isolation does not maintain neuropathic behavior (Porreca et al., 2002; Bee and Dickenson, 2007). It is therefore plausible that RVM painmodulating neurons, like the dorsal horn, are sensitized to tactile stimulation after nerve injury.

\section{References}

Barbaro NM, Heinricher MM, Fields HL (1989) Putative nociceptive modulatory neurons in the rostral ventromedial medulla of the rat display highly correlated firing patterns. Somatosens Mot Res 6:413-425.

Bederson JB, Fields HL, Barbaro NM (1990) Hyperalgesia during naloxoneprecipitated withdrawal from morphine is associated with increased oncell activity in the rostral ventromedial medulla. Somatosens Mot Res 7:185-203.

Bee LA, Dickenson AH (2007) Rostral ventromedial medulla control of spinal sensory processing in normal and pathophysiological states. Neuroscience 147:786-793.

Burgess SE, Gardell LR, Ossipov MH, Malan Jr TP, Vanderah TW, Lai J, Porreca F (2002) Time-dependent descending facilitation from the rostral ventromedial medulla maintains, but does not initiate, neuropathic pain. J Neurosci 22:5129-5136.

Campbell JN, Meyer RA (2006) Mechanisms of neuropathic pain. Neuron 52:77-92.

Chapman V, Suzuki R, Dickenson AH (1998) Electrophysiological characterization of spinal neuronal response properties in anaesthetized rats after ligation of spinal nerves L5-L6. J Physiol (Lond) 507:881-894.

Chu KL, Faltynek CR, Jarvis MF, McGaraughty S (2004) Increased WDR spontaneous activity and receptive field size in rats following a neuro-

\section{Neutral Cell}
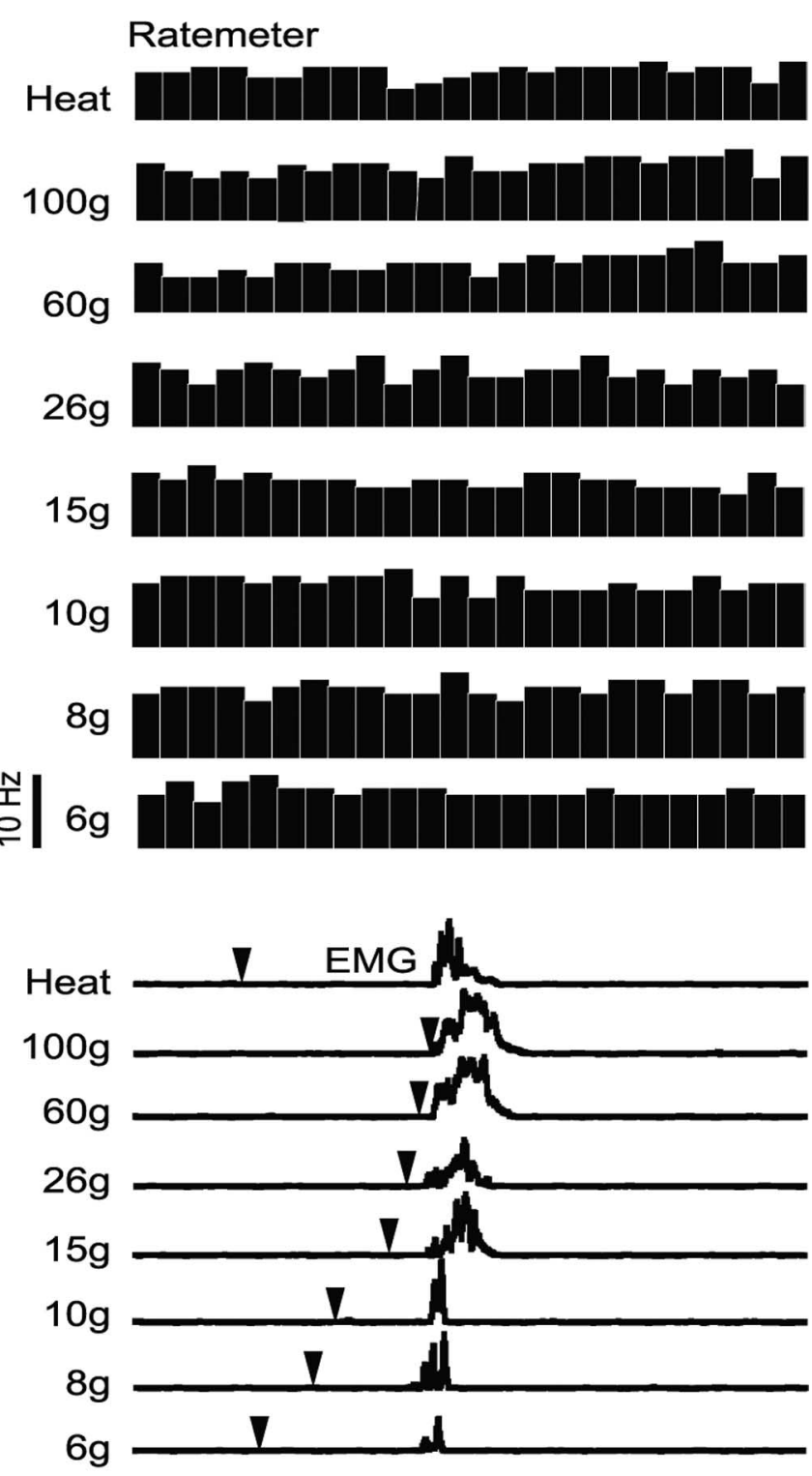

$5 \mathrm{~s}$

Figure 11. Example of neutral cell activity recorded during mechanical stimulation of the ligated paw in a nerve-injured animal. Ratemeter records demonstrate no neuronal response to either thermal (heat) or mechanical stimulation, although a withdrawal was evoked at innocuous through noxious stimulus forces, as shown in EMG recordings below. Stimulus onset is indicated by downward pointing arrowheads; as shown in group data (Fig. 4), withdrawal latency decreased with increasing stimulus force.

pathic or inflammatory injury: implications for mechanical sensitivity. Neurosci Lett 372:123-126.

Ellrich J, Ulucan C, Schnell C (2000) Are "neutral cells" in the rostral ventro-medial medulla subtypes of on- and off-cells? Neurosci Res 38:419-423.

Fields HL, Heinricher MM (1985) Anatomy and physiology of a nociceptive modulatory system. Philos Trans R Soc Lond B Biol Sci 308:361-374.

Fields HL, Bry J, Hentall I, Zorman G (1983) The activity of neurons in the rostral medulla of the rat during withdrawal from noxious heat. J Neurosci 3:2545-2552.

Fields HL, Basbaum AI, Heinricher MM (2005) Central nervous system mechanisms of pain modulation. In: Wall and Melzack's textbook of pain, Ed 5 (McMahon S, Koltzenburg M, eds), pp 125-142. London: Elsevier. Guan Y, Terayama R, Dubner R, Ren K (2002) Plasticity in excitatory amino 
acid receptor-mediated descending pain modulation after inflammation. J Pharmacol Exp Ther 300:513-520.

Guo W, Robbins MT, Wei F, Zou S, Dubner R, Ren K (2006) Supraspinal brain-derived neurotrophic factor signaling: a novel mechanism for descending pain facilitation. J Neurosci 26:126-137.

Heinricher MM, Ingram SL (2007) The brainstem and nociceptive modulation. In: Handbook of the senses, Vol 3, Pain (Basbaum AI, Bushnell $\mathrm{MC}$, Julius D, eds), in press. London: Elsevier.

Heinricher MM, Neubert MJ (2004) Neural basis for the hyperalgesic action of cholecystokinin in the rostral ventromedial medulla. J Neurophysiol 92:1982-1989.

Heinricher MM, Tortorici V (1994) Interference with GABA transmission in the rostral ventromedial medulla: disinhibition of off-cells as a central mechanism in nociceptive modulation. Neuroscience 63:533-546.

Heinricher MM, Barbaro NM, Fields HL (1989) Putative nociceptive modulating neurons in the rostral ventromedial medulla of the rat: firing of on- and off-cells is related to nociceptive responsiveness. Somatosens Mot Res 6:427-439.

Heinricher MM, Morgan MM, Tortorici V, Fields HL (1994) Disinhibition of off-cells and antinociception produced by an opioid action within the rostral ventromedial medulla. Neuroscience 63:279-288.

Heinricher MM, Neubert MJ, Martenson ME, Gonçalves L (2004) Prostaglandin $\mathrm{E}_{2}$ in the medial preoptic area produces hyperalgesia and activates pain-modulating circuitry in the rostral ventromedial medulla. Neuroscience 128:389-398.

Imbe H, Okamoto K, Okamura T, Kumabe S, Nakatsuka M, Aikawa F, IwaiLiao Y, Senba E (2005) Effects of peripheral inflammation on activation of ERK in the rostral ventromedial medulla. Brain Res 1063:151-158.

Imbe H, Okamoto K, Aikawa F, Kimura A, Donishi T, Tamai Y, Iwai-Liao Y, Senba E (2007) Effects of peripheral inflammation on activation of p38 mitogen-activated protein kinase in the rostral ventromedial medulla. Brain Res 1134:131-139.

Jinks SL, Carstens E, Antognini JF (2004) Isoflurane differentially modulates medullary $\mathrm{ON}$ and OFF neurons while suppressing hind-limb motor withdrawals. Anesthesiology 100:1224-1234.

Jinks SL, Carstens EE, Antognini JF (2007) Glutamate receptor blockade in the rostral ventromedial medulla reduces the force of multisegmental motor responses to noxious stimuli. Neurosci Lett 426:175-180.

Kim SH, Chung JM (1992) An experimental model for peripheral neuropathy produced by segmental spinal nerve ligation in the rat. Pain 50:355-363.

Kincaid W, Neubert MJ, Xu M, Kim CJ, Heinricher MM (2006) Role for medullary pain facilitating neurons in secondary thermal hyperalgesia. J Neurophysiol 95:33-41.

Kovelowski CJ, Ossipov MH, Sun H, Lai J, Malan TP, Porreca F (2000) Supraspinal cholecystokinin may drive tonic descending facilitation mechanisms to maintain neuropathic pain in the rat. Pain 87:265-273.

Luukko M, Pertovaara A (1993) Influence of an experimental peripheral mononeuropathy on the responses of medial bulboreticular neurons to noxious skin stimulation and the modulation of the responses by an alpha 2-adrenoceptor agonist in the rat. Exp Neurol 124:390-394.

Martenson ME, Heinricher MM (2007) Stress-induced hyperalgesia: recruitment of the rostral ventromedial medulla by stimulation of the dorsomedial hypothalamus. Soc Neurosci Abstr 33:723.11.

Mason P (2005) Deconstructing endogenous pain modulations. J Neurophysiol 94:1659-1663.

Miki K, Zhou QQ, Guo W, Guan Y, Terayama R, Dubner R, Ren K (2002) Changes in gene expression and neuronal phenotype in brain stem pain modulatory circuitry after inflammation. J Neurophysiol 87:750-760.

Millecamps M, Centeno MV, Berra HH, Rudick CN, Lavarello S, Tkatch T, Apkarian AV (2007) D-Cycloserine reduces neuropathic pain behavior through limbic NMDA-mediated circuitry. Pain 132:108-123.

Neubert MJ, Kincaid W, Heinricher MM (2004) Nociceptive facilitating neurons in the rostral ventromedial medulla. Pain 110:158-165.

Oliveras JL, Montagne-Clavel J, Martin G (1991a) Drastic changes of ventromedial medulla neuronal properties induced by barbiturate anesthe- sia. I. Comparison of the single-unit types in the same awake and pentobarbital-treated rats. Brain Res 563:241-250.

Oliveras JL, Martin G, Montagne-Clavel J (1991b) Drastic changes of ventromedial medulla neuronal properties induced by barbiturate anesthesia. II. Modifications of the single-unit activity produced by brevital, a short-acting barbiturate in the awake, freely moving rat. Brain Res 563:251-260.

Ossipov MH, Lai J, King T, Vanderah TW, Malan Jr TP, Hruby VJ, Porreca F (2004) Antinociceptive and nociceptive actions of opioids. J Neurobiol 61:126-148.

Palecek J, Dougherty PM, Kim SH, Paleckova V, Lekan H, Chung JM, Carlton SM, Willis WD (1992) Responses of spinothalamic tract neurons to mechanical and thermal stimuli in an experimental model of peripheral neuropathy in primates. J Neurophysiol 68:1951-1966.

Paxinos G, Watson C (1997) The rat brain in stereotaxic coordinates, Ed 3. Sydney: Academic.

Pertovaara A, Wei H (2000) Attenuation of ascending nociceptive signals to the rostroventromedial medulla induced by a novel alpha2-adrenoceptor agonist, MPV-2426, following intrathecal application in neuropathic rats. Anesthesiology 92:1082-1092.

Pertovaara A, Wei H, Hamalainen MM (1996) Lidocaine in the rostroventromedial medulla and the periaqueductal gray attenuates allodynia in neuropathic rats. Neurosci Lett 218:127-130.

Pertovaara A, Kontinen VK, Kalso EA (1997) Chronic spinal nerve ligation induces changes in response characteristics of nociceptive spinal dorsal horn neurons and in their descending regulation originating in the periaqueductal gray in the rat. Exp Neurol 147:428-436.

Pertovaara A, Keski-vakkuri U, Kalmari J, Wei H, Panula P (2001) Response properties of neurons in the rostroventromedial medulla of neuropathic rats: attempted modulation of responses by [1DME]NPYF, a neuropeptide FF analogue. Neuroscience 2001:457-468.

Pitcher GM, Henry JL (2000) Cellular mechanisms of hyperalgesia and spontaneous pain in a spinalized rat model of peripheral neuropathy: changes in myelinated afferent inputs implicated. Eur J Neurosci 12:2006-2020.

Porreca F, Burgess SE, Gardell LR, Vanderah TW, Malan Jr TP, Ossipov MH, Lappi DA, Lai J (2001) Inhibition of neuropathic pain by selective ablation of brainstem medullary cells expressing the m-opioid receptor. J Neurosci 21:5281-5288.

Porreca F, Ossipov MH, Gebhart GF (2002) Chronic pain and medullary descending facilitation. Trends Neurosci 25:319-325.

Schnell C, Ulucan C, Ellrich J (2002) Atypical on-, off- and neutral cells in the rostral ventromedial medulla oblongata in rat. Exp Brain Res 145:64-75

Suzuki R, Rygh LJ, Dickenson AH (2004) Bad news from the brain: descending 5-HT pathways that control spinal pain processing. Trends Pharmacol Sci 25:613-617.

Tracey I, Mantyh PW (2007) The cerebral signature for pain perception and its modulation. Neuron 55:377-391.

Wei F, Dubner R, Ren K (1999) Nucleus reticularis gigantocellularis and nucleus raphe magnus in the brain stem exert opposite effects on behavioral hyperalgesia and spinal fos protein expression after peripheral inflammation. Pain 80:127-141.

Winkler CW, Hermes SM, Chavkin CI, Drake CT, Morrison SF, Aicher SA (2006) Kappa opioid receptor (KOR) and GAD67 immunoreactivity are found in OFF and neutral cells in the rostral ventromedial medulla. J Neurophysiol 96:3465-3473.

Xu M, Kim CJ, Neubert MJ, Heinricher MM (2007) NMDA receptormediated activation of medullary pro-nociceptive neurons is required for secondary thermal hyperalgesia. Pain 127:253-262.

Zhang L, Sykes KT, Buhler AV, Hammond DL (2006) Electrophysiological heterogeneity of spinally-projecting serotonergic and non-serotonergic neurons in the rostral ventromedial medulla. J Neurophysiol 95:1853-1863.

Zimmermann M (1983) Ethical guidelines for investigation of experimental pain in conscious animals. Pain 16:109-110. 